\title{
Model Hub Median Problem Dengan Batasan Travel Time
}

\author{
Muhammad Faisal Ibrahim*, Ahmad Rusdiansyah \\ Jurusan Teknik Industri, Fakultas Teknologi Industri, Institut Teknologi Sepuluh Nopember \\ Jl. Raya ITS, Sukolilo, Surabaya 60111 \\ *Surel: faisalibrahim.ie@gmail.com
}

\begin{abstract}
This article describes the development of an uncapacitated $p$-hub median problem model. The established model will be applied in determining the location of the hub. Generally in the median p-hub model problem, it is known that the number of hubs built with the total cost minimization function. In this developed model, there is no limit to the number of hubs and the function of the intended destination is how many hubs are built. The model also looks for where the hub location will be built and which nodes are allocated to each hub. By eliminating the limitation of the number of hubs built, the model adds a total total timeout limit. The numerical experiments are dealing with the model. The solution to solve the model using excel solver. So that it will be designed spread sheet excel appropriate model. In numerical experiments, dummy data representing real systems will be used with the aim of shortening computational time. Numerical experiments are performed in several conditions scenarios. Computational results generate the location of hubs and nodes allocated to each hub with various experimental scenarios.
\end{abstract}

Keywords: Uncapacitated hub, travel time, median problem.

\begin{abstract}
Abstrak
Pada artikel ini menjelaskan pengembangan model uncapacitated p-hub median problem. Model yang dibentuk akan diaplikasikan dalam menentukan lokasi hub. Umumnya pada model p-hub median problem, diketahui jumlah hub yang dibangun dengan fungsi tujuan minimalisasi total biaya. Pada model yang dikembangkan ini, tidak ada batasan jumlah hub dan fungsi tujuan yang dicari adalah berapa jumlah hub yang dibangun. Model juga mencari di mana lokasi hub akan dibangun serta node mana saja yang dialokasikan pada masing-masing hub. Dengan menghilangkan batasan jumlah hub yang dibangun, model menambahkan batasan total waktu tempuh maksimal. Persobaan numerik dilakukan terhadap model tersebut. Solusi penyelesaian model menggunakan solver excel. Sehingga akan dirancang spread sheet excel yang sesuai model. Dalam percobaan numerik, data dummy yang merepresentasikan sistem nyata akan digunakan dengan tujuan mempersingkat waktu komputasi. Percobaan numerik dilakukan dalam beberapa skenario kondisi. Hasil komputasi menghasilkan lokasi hub dan node yang dialokasikan pada masing-masing hub dengan berbagai skenario percobaan.
\end{abstract}

Kata kunci: Uncapacitated hub, travel time, median problem.

\section{Pendahuluan}

Problem lokasi hub menjadi penting ketika diperlukan dalam kegiatan transportasi baik barang maupun penumpang dari tempat asal ke tempat tujuan. Hub adalah fasilitas khusus yang bertindak sebagai titik transfer [1]. Produk di pusatkan dan didistribusikan terlebih dahulu ke $h u b$ yang ada, sebelum didistribusikan lebih lanjut ke tujuan yang ada. Transportasi langsung dari satu titik asal ke satu titik tujuan memang lebih efektif, namun hal tersebut tidak dapat direalisasikan karena faktanya membangun jaringan seperti itu akan menjadi sangat mahal. Sebagai salah satu alternatif, jaringan logistik khusus dengan struktur hub dan spoke menjadi layak 
untuk dilakukan. Menurut Khosravi and Akbari Jokar [2] permintaan yang terjadi pada suatu daerah akan tergantung dari fasilitas yang berada pada daerah tersebut. Salah satu fasilitas yang dimaksud adalah $h u b$. Secara umum hub dan spokes dapat dilihat pada Gambar 1. Pada jaringan tersebut hub bertindak sebagai titik pengumpulan, konsolidasi, transfer, dan distribusi. Dengan menggunakan $h u b$, beberapa keuntungan dapat dicapai salah satunya adalah menghilangkan beban langsung pada manufaktur [3]. Dengan mengonsolidasikan aliran, skala ekonomi dapat dicapai sehingga biaya perpindahan barang antara $h u b$ lebih murah daripada biaya memindahkan barang secara langsung tidak melalui hub. Spokes dapat terhubung ke lebih dari satu hub, tergantung menggunakan alokasi tunggal atau ganda. Umumnya diasumsikan bahwa $h u b$ sepenuhnya saling berhubungan satu dan lainnya, sementara spokes tidak terhubung satu sama lain. Oleh karena itu semua barang harus disalurkan melalui setidaknya satu $h u b$. Oleh karena itu jaringan logistik terdiri dari dua bagian, yaitu level $h u b$ dan level spoke.

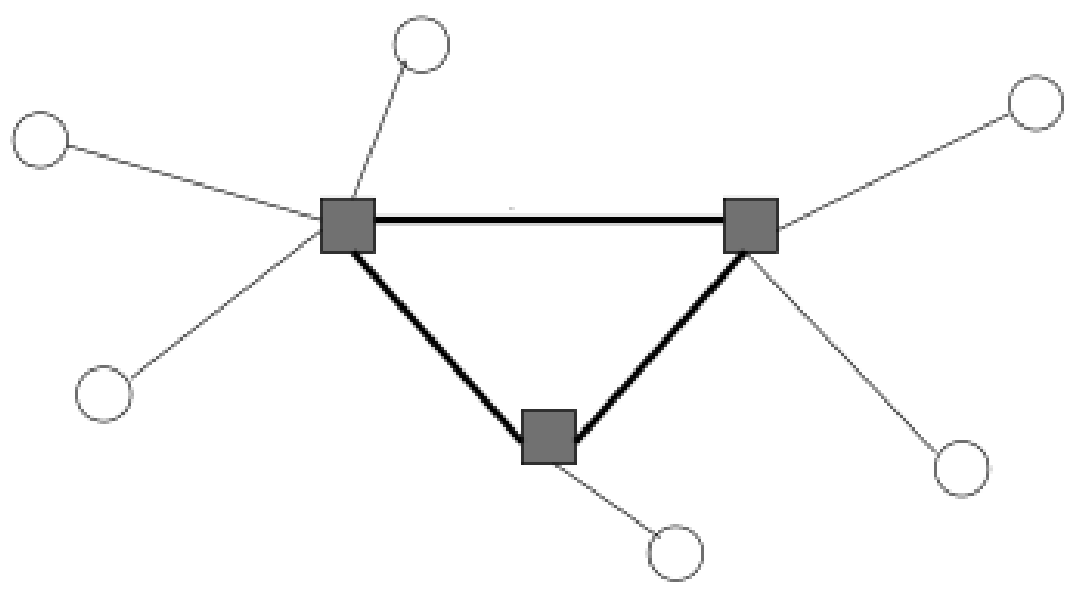

Gambar $1 \mathrm{Hub}$ dan spoke

$H u b$ median problem adalah suatu permasalahan penentuan lokasi fasilitas $h u b$ pada sebuah jaringan dan mengalokasikan nodes non hub ke node hub sehingga dapat meminimumkan total biaya transportasi [4]. Sedangkan P-hub max covering problem bertujuan untuk mencari lokasi terbaik $h u b$ sehingga dapat memaksimasi demand sepanjang coverage distance hub tersebut [5]. Pada umumnya, perusahaan akan menangani masalah penugasan $h u b$ yang berbeda. Yang pertama adalah pemilihan $h u b$, yaitu node mana yang dipilih sebagai tempat pembangunan $h u b$. Sedangkan yang kedua adalah alokasi, di mana perusahaan akan menetapkan node spoke akan melewati hub yang mana. Pada banyak penelitian tentang hub location problem baik lokasi dan alokasi dikenal sebagai NP-hard problem. Beberapa penelitian yang membahas hub location problem menyebut problem ini dengan Uncapacitated Single Allocation P-Hub Median Problem USApHMP. Dalam masalah ini tidak ada pembatas kapasitas pada $h u b$, sehingga akan dipilih sejumlah $p$-hub dari node yang akan menjadi $h u b$. Kemudian akan akan dialokasikan spokes atau node lainnya yang tidak menjadi $h u b$ ke masingmasing $h u b$, sehingga jarak maksimum antara setiap pasangan dapat diminimalkan. Menurut Kara and Tansel [6], umumnya dalam pengiriman barang yang sensitif terhadap waktu akan membutuhkan sumber daya yang lebih, contohnya hub sehingga dapat melakukan pengiriman pada batasan waktu yang sebelunya tidak memungkinkan. 


\section{Metode Penelitian}

\subsection{Karakteristik Sistem}

Sistem nyata yang menjadi ide dalam pengembangan model ini adalah sistem transportasi dari satu titik keberangkatan menuju ke titik tujuan. Secara umum sistem seperti ini biasanya digunakan dalam proses pengiriman barang. Hub yang didirikan berfungsi sebagai tempat pengumpulan barang dari berbagai node, konsolidasi, dan selanjutnya didistribusikan ke node tujuan. Dapat dilihat pada Gambar 2, terdapat 2 $h u b$ yang menghubungkan 9 node atau kota berbeda. Hub pertama berada pada node 2, dan $h u b$ kedua berada pada node 6. Masing-masing $h u b$ tersebut akan melayani node $h u b$ tersbut didirikan dan node lainnya. Karena node atau kota-kota tidak terhubung secara langsung, sehingga $h u b$ yang didirikan akan menghubungkan semua kota. Sebagai contoh, barang yang dikirim dari kota 1 ke kota 5 akan dikirim ke hub 2 dahulu kemudian $h u b 2$ mengirimkannya kepada $h u b 6$ dan diteruskan ke kota tujuan yaitu kota 5. Pada model ini diasumsikan waktu minimum yang diperlukan adalah waktu terpanjang dari kota ke hub yang melayaninya. Kemudian ditambahkan waktu terpanjang dari $h u b$ selanjutnya ke kota tujuan. Diasumsikan juga kendaraan akan kembali lagi ke titik keberangkatan, sehingga total waktu yang dibutuhkan adalah dua kali perjalanan dari titik keberangkatan ke titik tujuan. Diasumsikan juga kendaraan yang digunakan satu dan tidak memiliki batasan kapasitas. Sehingga nanti dapat menghasilkan keputusan di mana lokasi $h u b$ akan didirikan dan kota mana saja yang dialokasikan pada masing-masing $h u b$.

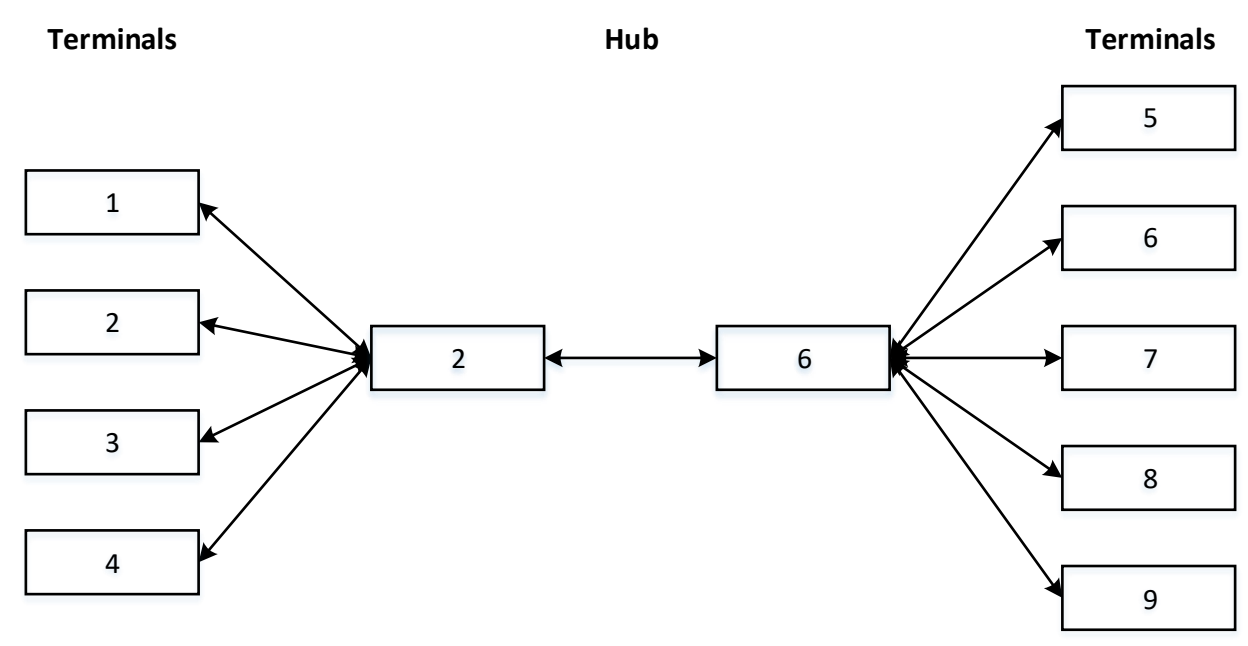

Gambar 2 Gambaran umum model

\subsection{Pengembangan model}

Model pada penelitian ini menggunakan pengembangan model median problem dan Uncapacitated Single Allocation P-Hub Median Problem USApHMP dalam menentukan $h u b$ yang akan dibangun. Model-model terdahulu yang dalam penentuan $h u b$ umumnya memiliki fungsi tujuan minimasi total cost. Hoff, et al. [7] melakukan penelitian tentang hub location problem berfokus pada fungsi tujuan meminimalkan biaya transportasi. Puerto, et al. [8] melakukan penelitian tentang hub location dengan fungsi tujuan minimalisasi biaya operasi dan alokasi. Silva and Cunha [9] melakukan penelitian dengan fokus pada lokasi terbaik dari $h u b$ yang akan dibangun. Model $h u b$ covering problem yang dikembangkan pada penelitian ini mengadopsi model yang 
sebelumnya telah dibahas oleh Kara and Tansel [6]. Pada model yang dikembangkan ini, fungsi tujuan yang dicari adalah meminimumkan jumlah hub yang akan dibangun. Sehingga akan dilakukan relaxation batasan jumlah hub. Akan ditambahkan juga batasan maksimum service, yaitu satu hub hanya dapat melayani maksimal $C$ node. Batasan lainnya yang ditambahkan adalah batasan maksimal waktu perjalanan Max T, yaitu dari berangkat sampai dengan kembali. Seperti model hub covering problem pada umumnya, akan dicari lokasi $h u b$ akan dibangun. Pada model yang dikembangkan ini tidak memerhatikan biaya pendirian hub. Model integer programing yang diusulkan adalah sebagai berikut.

Fungsi Tujuan :

MINIMIZE $\sum_{k} y i \quad \forall i$

dengan batasan-batasan sebagai berikut :

SUBJECT TO :

$\sum_{j} X_{i j}=1$

$\forall i$

$X_{i j}-y_{j} \leq 0 \quad \forall i, j$

$\sum_{j} X_{i j}-C y_{j} \leq 0 \quad \forall i$

$\sum_{j} \operatorname{MaxT}_{i j} X_{i j} \leq \operatorname{Max} T \quad \forall j$

$y_{j}=0,1$

$\forall j$

$X_{i j}=0,1$

$\forall i, j$

Fungsi tujuan pada model (1)adalah minimalisasi total $h u b$ yang akan dibangun. Fungsi tujuan tersebut bergantung kepada beberapa pembatas. Pembatas (2) memastikan bahwa setiap node ditugaskan ke tepat 1 hub j. pembatas (3) akan menghubungkan variabel lokasi $y_{j}$ dan variabel alokasi $X_{i j}$. Menyatakan node i dapat dilayani oleh fasilitas di node $\mathrm{j}\left(X_{i j}=1\right)$ jika sebuah fasilitas dilokasikan pada node $\mathrm{j}$ $\left(y_{j}=1\right)$. Karena $h u b$ yang dibangun hanya dapat melayani node dengan jumlah terbatas C, maka kendala (4) akan memastikan hub pada lokasi yj dapat melayani sejumlah $\mathrm{C}$ node termasuk node tersebut. Diasumsikan pengiriman menggunakan satu kendaraan dan tergantung pada waktu perjalanan masing-masing node. Perjalanan akan dilakukan dari satu node ke node lain melalui $h u b$ yang telah ditentukan dan kembali lagi ke node tersebut. Waktu perjalanan total $\max T$ akan menjadi batasan dalam model ini.Sehingga batasan (5) akan memastikan bahwa waktu perjalanan total tidak melebihi batasan max T. Pembatas (6), (7) menyatakan bahwa $y_{j}$ dan $X_{i j}$ adalah variabel biner $(0,1)$.

\section{Hasil dan Pembahasan}

Data utama yang diperlukan adalah data waktu tempuh perjalanan karena penentuan lokasi dan alokasi $h u b$ diawali dengan penyusunan matriks waktu perjalanan dari masing-masing node i ke j. Diasumsikan waktu perjalanan dari i ke $\mathrm{j}$ sama dengan dari $\mathrm{j}$ ke i. Matriks waktu perjalanan yang digunakan merupakan dummy problem bersekala kecil yang merepresentasikan sistem nyata. Penggunaan data dummy ini diputuskan dengan tujuan mempersingkat waktu komputasi. Namun data dummy yang digunakan, sebagian besar diambil dari penelitian-penelitian terdahulu sehingga diharapkan dapat merepreentasikan sistem nyata dengan baik. Langkah selanjutnya adalah menentukan jumlah node maksimum yang dapat dilayani oleh satu $h u b$. Kemudian juga akan ditentukan total waktu maksimal yang diperbolehkan dalam perjalanan. Akan dilakukan analisa sensitivitas pada beberapa variabel, di antaranya 
adalah jumlah node yang dapat dilayani satu $h u b(\mathrm{C})$, dan total waktu maksimal yang diperbolehkan (T). Matriks waktu tempuh antara node i ke j dapat dilihat pada Tabel 1.

Karena percobaan numerik akan dilakukan menggunakan solver MS. excel, sehingga harus dilakukan perancangan solver pada MS. Excel. Penulis menggunakan MS. Excel 2016 dengan spesifikasi komputer RAM 4 GB. Lembar kerja MS. Excel akan dirancang sesuai dengan model matematis yang telah diformulasikan sebelumnya, sehingga dapat menghasilkan fungsi tujuan yang diinginkan. Hasil perancangan solver MS. Excel dapat dilihat pada Gambar 3 dan Gambar 4.

Tabel 1 Matriks waktu tempuh

\begin{tabular}{lccccc}
\hline & \multicolumn{5}{c}{ Tij } \\
\hline & 1 & 2 & 3 & 4 & 5 \\
\cline { 2 - 6 } 1. Lowokwaru & 0 & 4 & 9 & 10 & 6 \\
2. Singosari & 4 & 0 & 9 & 8 & 4 \\
3. Dau & 9 & 9 & 0 & 4 & 3 \\
4. Klojen & 10 & 8 & 4 & 0 & 7 \\
5. Sumbersari & 6 & 4 & 3 & 7 & 0 \\
\hline
\end{tabular}

Analisa sensitivitas dilakukan dengan mencoba beberapa variasi jumlah node yang dapat dilayani.oleh satu $h u b$ (C) dan maksimum waktu perjalanan yang diperbolehkan (Max T). Hasil dari analisa sensitivitas dengan mencoba variasi nilai C dapat dilihat pada Tabel 2.

Tabel 2 Hasil komputasi dengan variasi nilai C

\begin{tabular}{|c|c|c|c|c|}
\hline $\mathrm{C}$ & $\mathrm{Y}$ & $\mathrm{T}$ & Location of $y$ & Covered \\
\hline 5 & 1 & 14 & 5 & $1,2,3,4,5$ \\
\hline \multirow{2}{*}{4} & \multirow{2}{*}{2} & \multirow{2}{*}{28} & 1 & $1,3,4$ \\
\hline & & & 2 & 2,5 \\
\hline \multirow{2}{*}{3} & \multirow{2}{*}{2} & \multirow{2}{*}{16} & 2 & $1,2,5$ \\
\hline & & & 3 & 3,4 \\
\hline \multirow{3}{*}{2} & \multirow{3}{*}{3} & \multirow{3}{*}{22} & 1 & 1 \\
\hline & & & 4 & 2,4 \\
\hline & & & 5 & 3,5 \\
\hline
\end{tabular}

Dapat dilihat pada Tabel 2, jarak tempuh minimum sebesar 14 menit didapatkan saat menggunakan satu $h u b$ untuk seluruh node. Hal ini menjadi layak karena problem yang digunakan memiliki skala yang kecil. Sehingga kesempatan menggunakan satu $h u b$ menjadi lebih besar dalam problem yang kecil. Penulis juga melakukan percobaan dengan merubah jumlah node yang dapat dilayani oleh satu hub (C). Jika nilai $\mathrm{C}$ diturunkan menjadi 4, maka akan didirikan 2 hub yaitu pada node 1 dan 2 dengan waktu perjalanan $\mathrm{T}$ sebesar 28 menit. Jika nilai $\mathrm{C}$ diturunkan menjadi 3, maka akan didirikan 2 hub yaitu pada node 2 dan 3 dengan waktu perjalanan T sebesar 16 menit. Dan jika nilai $\mathrm{C}$ diturunkan menjadi 2, maka akan didirikan 3 hub yaitu pada node 1, 4, dan 5 dengan waktu perjalanan $\mathrm{T}$ sebesar 22 menit. 


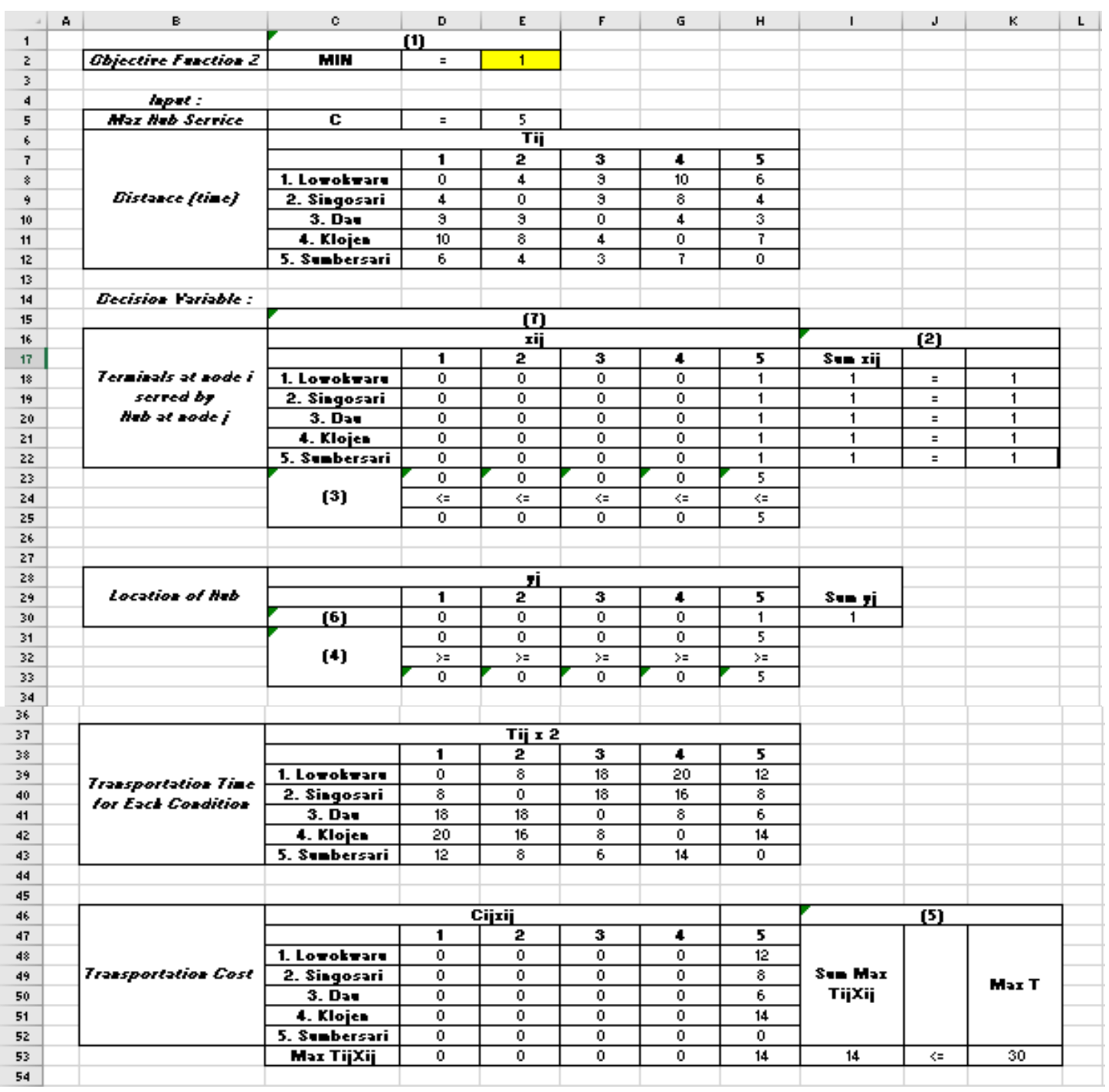

Gambar 3 Rancagan solver excel

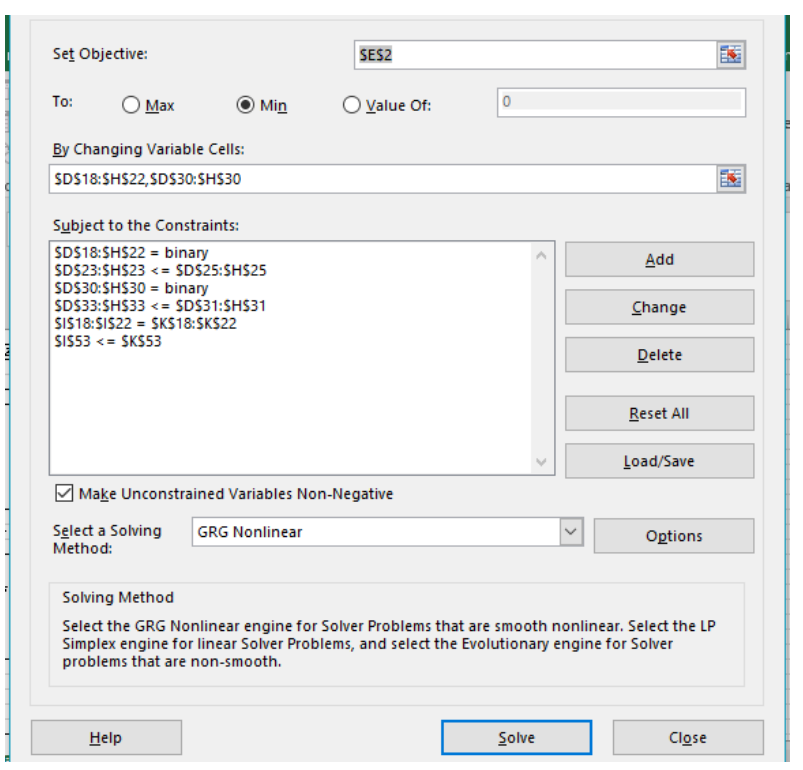

Gambar 4 Rancagan solver excel 
Tabel 3 Hasil komputasi dengan variasi nilai Max T

\begin{tabular}{|c|c|c|c|c|}
\hline \multicolumn{5}{|c|}{$\mathrm{C}=4$} \\
\hline $\operatorname{Max} \mathbf{T}$ & $\mathbf{Y}$ & $\mathbf{T}$ & Location of $y$ & Covered \\
\hline \multirow{2}{*}{30} & \multirow{2}{*}{2} & \multirow{2}{*}{20} & 3 & $1,2,3$ \\
\hline & & & 5 & 4,5 \\
\hline \multirow{2}{*}{18} & \multirow{2}{*}{2} & \multirow{2}{*}{18} & 1 & 1 \\
\hline & & & 2 & $2,3,4,5$ \\
\hline \multicolumn{5}{|c|}{$\mathrm{C}=3$} \\
\hline $\operatorname{Max} \mathbf{T}$ & $\mathbf{Y}$ & $\mathbf{T}$ & Location of $y$ & Covered \\
\hline \multirow{2}{*}{25} & \multirow{2}{*}{2} & \multirow{2}{*}{22} & 2 & $1,2,3$ \\
\hline & & & 5 & 4,5 \\
\hline \multirow{2}{*}{20} & \multirow{2}{*}{2} & \multirow{2}{*}{20} & 3 & 3,4 \\
\hline & & & 5 & $1,2,5$ \\
\hline \multirow{3}{*}{19} & \multirow{3}{*}{3} & \multirow{3}{*}{18} & 2 & 2 \\
\hline & & & 3 & $1,3,4$ \\
\hline & & & 5 & 5 \\
\hline \multicolumn{5}{|c|}{$\mathrm{C}=2$} \\
\hline $\operatorname{Max} \mathbf{T}$ & $\mathbf{Y}$ & $\mathbf{T}$ & Location of $y$ & Covered \\
\hline \multirow{3}{*}{25} & \multirow{3}{*}{3} & \multirow{3}{*}{24} & 2 & 2 \\
\hline & & & 3 & $1,3,4$ \\
\hline & & & 5 & 5 \\
\hline \multirow{3}{*}{23} & \multirow{3}{*}{3} & \multirow{3}{*}{16} & 1 & 1 \\
\hline & & & 2 & 2,5 \\
\hline & & & 4 & 3,4 \\
\hline \multirow{4}{*}{15} & \multirow{4}{*}{4} & \multirow{4}{*}{6} & 1 & 1 \\
\hline & & & 2 & 2 \\
\hline & & & 4 & 4 \\
\hline & & & 5 & 3,5 \\
\hline \multirow{5}{*}{4} & \multirow{5}{*}{5} & \multirow{5}{*}{5} & 1 & 1 \\
\hline & & & 2 & 2 \\
\hline & & & 3 & 3 \\
\hline & & & 4 & 4 \\
\hline & & & 5 & 5 \\
\hline
\end{tabular}

Variasi nilai Max T yang dapat dilihat pada Tabel 3. Sebagai contoh, saat nilai C sebesar 2 dengan waktu perjalanan max T sebesar 25 menit maka memerlukan $3 \mathrm{hub}$ dengan waktu perjalanan T sebesar 24 menit. Saat waktu perjalanan max T diturunkan menjadi 15 menit, diperlukan 4 hub dengan waktu perjalanan 6 menit.

\section{Simpulan}

Model hub covering problem usulan memberikan alternatif lokasi pembangunan $h u b$ yang akan dilakukan perusahaan. Dengan tambahan batasan kapasitas jumlah node yang dapat dilayani oleh satu $h u b$ maka dapat ditentukan jumlah minimal dan lokasi $h u b$ optimal. Percobaan dilakukan dengan data jarak waktu tempuh 5 lokasi yang harus di-cover oleh hub. Hasil dari percobaan, waktu tersingkat diperoleh saat perusahaan menggunakan $1 \mathrm{hub}$. Dengan menggunakan satu hub, hub akan didirikan di daerah Sumbersari dengan waktu tempuh minimum 14 menit. Terpilihnya satu $h u b$ sebagai $h u b$ optimal tidak lain karena skala kasus yang kecil sehingga satu $h u b$ menjadi optimal ketika $h u b$ tersebut dapat melayani seluruh node. Percobaan dilanjutkan dengan menurunkan jumlah node yang dapat dilayani oleh sebuah $h u b$. Jika hub hanya 
dapat melayani 4 node maka $h u b$ akan didirikan pada daerah Lowokwaru dan Singosari dan waktu tempuh minimumnya adalah 18 menit. Sedangkan jika hub hanya dapat melayani 3 node maka hub akan didirikan pada daerah Singosari dan Dau, dengan waktu tempuh minimumnya sebesar 16 menit. Dan jika hub hanya dapat melayani 2 node maka hub akan didirikan pada daerah Lowokwaru, Klojen, dan Sumbersari dan waktu tempuh minimumnya adalah 22 menit. Penelitian ini masih menggunakan waktu perjalanan yang bersifat konstan, akan lebih baik jika mempertimbangkan ketidakpastian pada waktu perjalanan. Model ini masih dapat dikembangkan dengan menambahkan variabel biaya, sehinga minimasi total biaya yang lebih baik dapat terjadi.

\section{Daftar Notasi}

$X_{i j}\left\{\begin{array}{c}1 \text { jika node i dialokasikan ke hub pada node } \mathrm{j} \\ 0 \text { jika tidak }\end{array}\right.$

$\mathrm{y}_{\mathrm{j}}\left\{\begin{array}{l}1 \text { jika melokasikan hub pada node } \mathrm{j} \\ 0 \text { jika tidak }\end{array}\right.$

$\mathrm{C}=$ jumlah maksimal node yang dapat dilayani oleh satu hub.

$\mathrm{T}_{\mathrm{ij}}=$ Waktu perjalanan yang diprlukan dalam dari node $\mathrm{i}$ ke $\mathrm{j}$.

$\mathrm{N}=\{1, \ldots, \mathrm{n}\}$ menjadi kumpulan node.

\section{Referensi}

[1] R. Martí, Á. Corberán, and J. Peiró, "Scatter search for an uncapacitated p-hub median problem," Computers \& Operations Research, vol. 58, pp. 53-66, 6// 2015.

[2] S. Khosravi and M. R. Akbari Jokar, "Facility and hub location model based on gravity rule," Computers \& Industrial Engineering, vol. 109, pp. 28-38, 7// 2017.

[3] C.-C. Lin, J.-Y. Lin, and Y.-C. Chen, "The capacitated p-hub median problem with integral constraints: An application to a Chinese air cargo network," Applied Mathematical Modelling, vol. 36, pp. 2777-2787, 6// 2012.

[4] A. T. Ernst, H. Hamacher, H. Jiang, M. Krishnamoorthy, and G. Woeginger, "Uncapacitated single and multiple allocation p-hub center problems," Computers \& Operations Research, vol. 36, pp. 2230-2241, 7// 2009.

[5] M. Peker and B. Y. Kara, "The P-Hub maximal covering problem and extensions for gradual decay functions," Omega, vol. 54, pp. 158-172, 7// 2015.

[6] B. Y. Kara and B. C. Tansel, "The single-assignment hub covering problem: Models and linearizations," Journal of the Operational Research Society, vol. 54, pp. 59-64, 2003.

[7] A. Hoff, J. Peiró, Á. Corberán, and R. Martí, "Heuristics for the Capacitated Modular Hub Location Problem," Computers \& Operations Research.

[8] J. Puerto, A. B. Ramos, and A. M. Rodríguez-Chía, "Single-allocation ordered median hub location problems," Computers \& Operations Research, vol. 38, pp. 559-570, 2// 2011.

[9] M. R. Silva and C. B. Cunha, "A tabu search heuristic for the uncapacitated single allocation p-hub maximal covering problem," European Journal of Operational Research, vol 262, pp. 954-965, 2017. 